\title{
Abortion in Turkey: women in rural areas and the law
}

\section{MATERNAL DEATHS AND UNSAFE ABORTIONS}

Worldwide, an estimated 529000 girls and women die of pregnancy-related causes each year, about one every minute, and many times that number suffer long-term injuries and disabilities. Ninety-nine percent of all maternal deaths occur in the developing world. ${ }^{1-5}$

Direct causes of pregnancy-related deaths worldwide are:

- severe bleeding, 25\%;

- infection, 15\%;

- unsafe abortion, $13 \%$;

- hypertensive disorders, $12 \%$;

- obstructed labour, 8\%; and

- other, $8 \%$.

Abortion is a sensitive and contentious issue with religious, moral, cultural, and political dimensions. It is also a public health concern in many parts of the world.

More than one-quarter of the world's people live in countries where the procedure is prohibited or permitted only to save the woman's life. Yet, regardless of legal status, abortions still occur, and nearly half of them are performed by an unskilled practitioner or in less than sanitary conditions, or both.

WHO defines an unsafe abortion as 'a procedure for terminating an unwanted pregnancy either by persons lacking the necessary skills or in an environment lacking the minimal medical standards, or both'. When abortion is performed by qualified people using correct techniques in sanitary conditions, it is very safe. Worldwide, nearly one in 10 pregnancies ends in unsafe abortion. But this is a global estimate, combining countries where abortion is safe and legal with those where it is restricted and often unsafe. In low-income countries, women have an average of one unsafe abortion during their reproductive lives. ${ }^{3,6-8}$

\section{COUNTRY PROFILE}

Turkey is currently the most populous country in the Middle East and one of the 20 most populous countries in the world. Women constitute 36.1 million of the population, and half of this number is of reproductive age. Each year approximately 1.5 million births take place and 728-1000 mothers die due to pregnancy-, delivery-, and birth-related complications.

Turkey has made progress in improving reproductive health since the 1994 International Conference on Population and Development (ICPD), and the government has reflected the ICPD targets and strategies in the country's Development Plan. Furthermore, a National Strategic Plan for Women's Health and Family Planning was developed, which highlights the need to reduce disparities between and within the regions and between different population groups. ${ }^{9-11}$

Despite some progress achieved in the area of primary mother-child health care and reproductive health, there are still serious gaps in the availability of healthcare services, particularly between urban and rural areas as opposed to towns and cities, and among the regions, especially for those living in the poorer eastern part of Turkey rather than in the west.

Induced abortion is a national problem in women's health, as it is for the whole world, and unsafe abortion is one of the major causes of death among women of reproductive age in Turkey.

Despite the liberal nature of the abortion law, the number of legal abortions up to 10 weeks performed in the country has been sharply restricted by the requirement that the procedure be carried out only by or under the supervision of gynaecologists. ${ }^{12,13}$ This factor is especially critical in rural Turkey, where medical specialists of any type are rare or non-existent. Many rural health facilities that are without a trained specialist are excluded from providing services. Consequently, a rural Turkish woman seeking an abortion within the first 10 weeks of pregnancy may not be able to obtain one.
This paper aims to emphasise that the law for safe abortion services may itself represent a barrier to service provision for all women of reproductive age.

\section{REPRODUCTIVE HEALTH PRIORITIES IN TURKEY}

In Turkey, the reproductive health status of the population, particularly women, is low compared to other countries at the same level of development. In spite of improved life expectancy, maternal and infant mortality rates are still above the regional averages, as compared with Europe. Some findings of the 2003 Turkish Demographic Health Survey (TDHS) may be significant in explaining the low status of reproductive health in the country: the level of unwanted pregnancies is $11 \%$, nearly one-fifth of pregnant women do not receive antenatal care, and one-fifth of births take place outside health facilities. In addition, nearly one-fifth of all births take place without the assistance of a doctor or trained health personnel. The use of modern contraceptives is low. Condom use among married men is around $11 \% .^{14}$

Turkey is ranked 94th out of 177 countries according to the Human Development Index for 2005, based on 2003 data. $^{15}$ The Human Development Report also indicates serious regional differences within the country. ${ }^{16}$

\section{URBAN-RURAL DIFFERENCES IN WOMEN'S REPRODUCTIVE HEALTH SERVICES}

In Turkey, the proportion of women not receiving any antenatal care is only $12 \%$ in urban areas whereas the figure stands at one-third for those living in rural areas. Mothers living in urban settlements are more likely to receive antenatal care from a doctor than those living in rural areas (84\% and $58 \%$, respectively). Many women in Turkey are aware of the importance of an early visit for antenatal care. More women in urban areas $(80 \%)$ seek antenatal care before the sixth month of pregnancy 
compared to women in rural areas $(52 \%)$. Antenatal care coverage exceeds $80 \%$ in all regions except the east, where it was received by $61 \%$ of mothers for the most recent births in the 5 years prior to the survey. Reflecting the greater tendency among rural women to delay seeking care, the median duration of pregnancy at the first antenatal visit is 2.6 months in urban areas and 3.5 months in rural areas.

This unmet need for family planning in Turkey fell from $10 \%$ in 1998 to $6 \%$ in 2003 , but this is higher among women aged 15-29 years and women living in rural accommodation. Unmet need by region varies from $3 \%$ of women in the west to $15 \%$ of women in the east. ${ }^{14}$

Limited access to and low utilisation of health services in the eastern and southeastern regions and rural areas throughout the country is often related to the low social status of families, especially of women.

\section{SCOPE OF INDUCED ABORTIONS}

The international health community and governments worldwide have repeatedly agreed that reducing deaths and injuries from unsafe abortion is a high priority. ${ }^{17}$

Although specific commitments have been made toward achieving this objective, progress to date has been wholly inadequate. Significant progress cannot occur until all women of reproductive age have much better access to safe abortion care in their communities. Abortion is safest when performed early in a pregnancy. Menstrual regulation is defined as any procedure which disrupts the intrauterine environment so that embryonic implantation either cannot occur or cannot be maintained. ${ }^{18}$ The technique is also known as menstrual aspiration, menstrual extraction, interception, and uterine aspiration. ${ }^{19}$ It can be performed using drugs, physical agents, and surgical techniques. The advent of vacuum aspiration in the 1960s revolutionised the primary prevention of complications in developing countries. This technology relies on the use of a simple syringe with a plunger to generate negative pressure for uterine evacuation, and plastic cannulas of varying sizes. The amount of negative pressure obtained with manual vacuum aspiration (MVA) is similar to that generated with large, expensive, electrical pumps, which makes this method especially suited for use in clinics, offices, and low-resource settings. MVA also has the advantage that the syringe can be cleaned, disinfected to a high level, or sterilised and used repeatedly; similarly, cannulas can be discarded or reused after appropriate disinfection or sterilisation. Vacuum aspiration is safer than sharp curettage, and the WHO recommends vacuum aspiration as the preferred method for uterine evacuation before 12 weeks of pregnancy. ${ }^{20,21}$

The vacuum aspiration method is also a safe, effective, and acceptable treatment for the treatment of first-trimester uncomplicated incomplete abortion, as is $600 \mu \mathrm{g}$ oral misoprostol. $22-24$

MVA is faster, safer, more comfortable, and associated with shorter hospital stay for induced abortion than sharp curettage..$^{25,26}$ Additional advantages compared with sharp curettage are its ease of use as an outpatient procedure, the need for less analgesia and anaesthesia, ${ }^{27}$ and its lower cost per procedure, especially if done on an outpatient basis..$^{28}$ In countries with a small number of physicians, vacuum aspiration can be safely and effectively used by mid-level health service providers, such as midwives. ${ }^{29,30}$

Studies from all over the world indicate that a wide range of medical and paramedical professionals can effectively and safely provide MVA services. In a 2006 study Warriner et al assessed whether the safety of first-trimester MVA abortion performed by healthcare providers who are not doctors (mid-level providers) is equivalent to that of procedures performed by doctors in South Africa and Vietnam, where mid-level providers are government trained and accredited to do first-trimester abortions. It was found that with appropriate government training, mid-level healthcare providers can provide first trimester MVA abortions as safely as doctors can. ${ }^{31-36}$

In Turkey, induced abortion has always been important in fertility regulation, even preceding it's legalisation on socioeconomic grounds in 1983 with the enactment of the new Population Planning Law. In the early 1980s, the growing incidence of unsafe abortion in Turkey and the resulting morbidity and mortality rates led the government to liberalise the law further and make abortion widely available. The Population Planning Law in 1983 provided safe abortion on request during the first 10 weeks of gestation for every woman who needed the service. ${ }^{12}$

Under this law, trained nurses and midwives are authorised to insert IUDs, and GPs and family physicians with special training are allowed to provide abortions by vacuum aspiration, under the supervision of obstetrician-gynaecologists. . $^{13,37,38}$

In rural areas of Turkey in particular, primary sometimes second-level healthcare facilities without obstetricians have to refer their abortion cases, even those with severe bleeding, to a higher level facility, leaving most women unable to obtain emergency care in time. ${ }^{39}$

Although the percentage of pregnancies that are ended through induced and unsafe abortion in Turkey have reduced, the level remains high due to this legal obligation.

\section{DISCUSSION}

All women should be entitled to safe pregnancy, safe delivery, and safe abortion. ${ }^{40,41,42}$

Access to safe abortion care can be a life or death issue for women. These deaths and injuries represent a social injustice of tragic proportions, particularly because they are almost entirely preventable compared to other main causes of 
maternal deaths. Deaths of women related to pregnancy contribute significantly to the greatest health disparity between rich and poor countries or regions.

Procedures and techniques for early induced abortion are both simple and safe. When performed by trained healthcare providers with appropriate equipment, using accurate techniques and good sanitary standards, abortion is one of the safest medical procedures. In most cases when women die or suffer permanent disability, it is because they do not receive medical treatment soon enough. ${ }^{43}$

According to one study of Turkish women whose abortions are legal and performed in medical clinics, mortality stands at 49 deaths per 100000 procedures, while among women whose abortions take place outside medical clinics, the risk of death is four times as high, at 208 deaths per 100000 procedures. ${ }^{44}$

Turkey has a socialised public health system that provides free primary health care to all citizens that require it, but abortion services and related procedures are restricted to obstetricians and the lack of obstetricians, especially in rural areas, limits women's access to safe abortion services in time. Because of this, women in rural areas who can afford competent services are more likely than women in urban areas to have an abortion performed at a private doctor's surgery rather than in hospitals or clinics. However, many women of low social and economic status face real dangers, such as death or permanent disability.

In Turkey, there are no accurate, routine statistical data for unsafe abortions, but according to research conducted in 1997 at 615 hospitals in 53 provinces that determined the main causes of maternal mortality, $4 \%$ of women died because of unsafe abortion complications $30.3 \%$ from haemorrhages, $15.5 \%$ from pregnancy related hypertension, and $9.6 \%$ from infection). ${ }^{15,45}$ However, because of abortions being kept secret or haemorrhage or sepsis being recorded as the final cause of death, we cannot obtain a complete picture. Despite this, unsafe abortion is clearly one of the major causes of maternal deaths in Turkey, as in other developing countries.
Experience from numerous countries demonstrates that, with appropriate training, supervision, and support, many mid-level healthcare providers such as nurses, midwives, clinical officers and others can safely and effectively offer abortion-related care that is both accessible and highly acceptable to women. Chaudhuri emphasised also that menstrual regulation is safe, involves an easy operation and can be performed not only by the doctors engaged in family planning work but also by GPs after some training. ${ }^{46}$

The studies carried out at different points of time, at different places and in different set-ups demonstrate that properly trained paramedical personnel could also perform the procedure as safely and effectively as physicians. The studies showed there is no substantial difference between complication rates of medical professionals and paramedics. ${ }^{47-50}$

Unfortunately in Turkey authorisation to perform abortions and related procedures are restricted to obstetricians. Mid-level healthcare providers, family physicians, and GPs may also conduct the procedure but only under the supervision of an obstetrician, even though they have been trained and certificated by the Ministry of Health. Significantly, family physicians and GPs are much more numerous, more geographically dispersed and more likely to work in rural areas than obstetricians.

If women's lives are to be saved, women's right to appropriate reproductive health services, including abortion care, must be secured by ensuring that women have access to these services in their communities. According to Grimes et al:

'Access to safe, legal abortion is a fundamental right of women, irrespective of where they live. The underlying causes of morbidity and mortality from unsafe abortion today are not blood loss and infection but, rather, apathy and disdain toward women. ${ }^{51}$

In conclusion, all countries should have a systematic plan and provide effective emergency medical care for women suffering from abortion complications. For efficient safe abortion care provision, health systems should treat abortion complications quickly and efficiently and guarantee that medical care, family planning, and other reproductive healthcare services are available and accessible to as many women as possible, especially at the primary healthcare level. To make this a reality, legal mechanisms should be re-examined even if they support safe abortion services. In addition, governments should plan to increase the number of service delivery sites offering abortion care and authorise all qualified healthcare personnel, regardless of their professional titles, to provide appropriate elements of abortion care services.

\section{Fusun Artiran Igde, Rukiye Gul, Mahir Igde and Murat Yalcin}

\section{REFERENCES}

1. AbouZahr C, Wardlaw T. Maternal mortality in 2000: estimates developed by WHO, UNICEF and UNFPA 2004. Geneva, Switzerland: World Health Organization, 2004.

2. Ashford L, Clifton D. Women of our world 2005. Washington DC: Population Reference Bureau [PRB], 2005.

3. World Health Organization (WHO). World health report 2005. Geneva, Switzerland: WHO, 2005.

4. United Nations Population Fund, UNFPA. State of world population 2005. The promise of equality: Gender equity, reproductive health and the Millenium Development Goals. New York, NY: UNFPA, 2005.

5. Tracy Geoghegan. State of the world's mothers 2004. Westport, CN: Save the Children, 2004.

6. World Health Organization (WHO). Unsafe abortion: global and regional estimates of the incidence of unsafe abortion and associated mortality in 2000. 4th edn. Geneva, Switzerland: WHO, 2004.

7. U.S. Centers for Disease Control and Prevention. Mortality and morbidity weekly review. In: Surveillance Summaries. Atlanta, GA: Centers for Disease Control and Prevention, 2003.

8. Shah I, Ahman E. Age patterns of unsafe abortion in developing country regions. Reprod Health Matters 2004; 12(24 Suppl): 9-17.

9. United Nations. Report of the International Conference on Population and Development, Cairo, 5-13 September 1994. New York, NY: UN, 1995.

10. Turkish Ministry of Health. Mother child health and family planning general directorate, National Women's Health and Family Planning Action Plan. Ankara, Turkey: Turkish Ministry of Health, 1998

11. Turkish Ministry of Health. National Strategies and Action Plan 2005-2015 for the Sexual Reproductive Health Sector. Ankara, Turkey: Mother Child Health and Family Planning General Directorate, 2005.

12. Government of Turkey. Population planning law. (Number 2827, sections 5 and 6). Official Turkish Gazette 27/05/1983-18059. http://www.mevzuat.adalet.gov.tr/html/613.html. (accessed 3 April 2008). 
13. Government of Turkey. Rules for service provision and supervision of menstrual regulation and sterilization. Ordinance No. 83/7395 of 14 November 1983, issued under Law No. 2827. Official Turkish Gazette 18/12/1983-18255. http://www.mevzuat.adalet.gov.tr/ html/5130.html. (accessed 3 April 2008).

14. Hacettepe University Institute of Population Studies, Turkish Ministry of Health. Turkey Demographic and Health Survey (TDHS-2003) Report. Ankara, Turkey: Mother Child Health and Family Planning General Directorate, 2004.

15. United Nations Development Programme. Human Development Report, 2005: International cooperation at a crossroads: aid, trade and security in an unequal world. New York: UNDP, 2005.

16. United Nations Development Programme. Human Development Reports. Turkey - major sustainable human development challenges in Turkey, 1995. Anakara, Turkey: Human Development Report Office, 1995

17. World Health Organization. Reduction of maternal mortality: a joint WHO/UNFPA/UNICEF/World Bank Statement. Geneva, Switzerland: WHO, 1999.

18. Brenner WE, Edelman DA. Menstrual regulation: risks and 'abuses'. Int J Gynaecol Obstet 1977; 15(2): 177-183.

19. Goldthorp WO. Ten-minute abortions. $\mathrm{Br}$ Med J 1977; 2(6086): 562-564

20. World Health Organization. Safe abortion: technical and policy guidance for health systems. Geneva, Switzerland: WHO, 2003.

21. Fortney JA, Vengadasalam D. Disposable menstrual regulation kits in a non-throw-away economy. Contraception 1980; 21(3): 235-244

22. Weeks A, Alia G, Blum J, et al. A randomized trial of misoprostol compared With manual vacuum aspiration for incomplete abortion. Obstet Gynecol 2005; 106(3): 540-547.

23. Macisaac L, Darney P. Early surgical abortion: an alternative to and backup for medical abortion. Am J Obstet Gynecol 2000; 183(2 Suppl): S76-83.

24. Forna F, Gulmezoglu AM. Surgical procedures to evacuate incomplete abortion. Cochrane Database Syst Rev 2001; (1): CD001993.

25. Cates W Jr. Legal abortion: the public health record. Science 1982; 215: 1586-1590.

26. Rogo K. Improving technologies to reduce abortionrelated morbidity and mortality. Int J Gynaecol Obstet 2004; 85(Suppl 1): S73-82.

27. Iyengar K, Iyengar SD. Elective abortion as a primary health service in rural India: experience with manual vacuum aspiration. Reprod Health Matters 2002; 10(19): 54-63.

28. Jowett M. Safe Motherhood interventions in lowincome countries: an economic justification and evidence of cost effectiveness. Health Policy 2000; 53(3): 201-228.

29. Sibuyi MC. Provision of abortion services by midwives in Limpopo Province of South Africa. Afr J Reprod Health 2004; 8(1): 75-78.

30. Westfall JM, Sophocles A, Burggraf H, Ellis S. Manual vacuum aspiration for first-trimester abortion. Arch Fam Med 1998; 7(6): 559-562.

31. Warriner IK, Meirik O, Hoffman M, et al. Rates of complication in first-trimester manual vacuum aspiration abortion done by doctors and mid-level providers in South Africa and Vietnam: a randomised controlled equivalence trial. Lancet 2006; 368(9551): 1965-1972.
32. Karman H. The paramedic abortionist. Clin Obstet Gynecol 1972; 15(2): 379-387.

33. Mtonga V, Ndhlovu M. Midwives' role in management of elective abortion and post-abortion care. Zambian country report. Presented at: Expanding Access; Advancing the Roles of Midlevel Providers in Menstrual Regulation and Elective Abortion Care. Pilanesberg National Park, South Africa, 2-6 December 2001.

(http://www.ipasihcar.net/expacc/reports/ZRepF.PDF accessed 3 April 2008).

34. Freedman MA, Jillson DA, Coffin RR, Novick LF. Comparison of complication rates in first trimester abortions performed by physician assistants and physicians. Am J Public Health 1986; 76(5): 550-554.

35. Dovlo D. Using mid-level cadres as substitutes for internationally mobile health professionals in Africa. A desk review. Hum Resour Health 2004; 2(1): 7

36. Horrocks E, Anderson C, Salisbury A. Systematic review of whether nurse practitioners working in primary care can provide equivalent care to doctors. BMJ 2002; 324(7341): 819-823

37. Greenslade Forrest C, Leonard AH, et al. Manua vacuum aspiration: a summary of clinical and programmatic experience worldwide. Stud Fam Plann 1993; 25(1): 64 .

38. Hessini L. Abortion and Islam: policies and practice in the Middle East and North Africa. Reprod Health Matters 2007; 15(29): 75-84.

39. MClaurin KE. A pro-active approach: meeting women's needs for abortion care in restrictive environments. Presented at: 119th Annual Meeting of the American Public Health Association. Atlanta, Georgia, 11-14 November 1991.

40. Safe motherhood fact sheets: Colombo Technical Consultation, October 1997. New York: Family Care International, 1998.

41. World Health Organisation (WHO). Reduction of maternal mortality. A joint WHO/UNFPA/UNICEF/ World Bank statement. Geneva, Switzerland: WHO, 1999.

42. World Health Organisation (WHO). The MotherBaby Package: An Overview, WHO/FHE/MSM/95.5. Geneva, Switzerland: WHO, 1995.

43. World Health Organisation (WHO). Complications of abortion: Technical and managerial guidelines for prevention and treatment. Geneva, Switzerland: WHO, 1995

44. Ladjali M, Hammand J, et al. Unsafe abortion and sexual health in the Arab world: the Damascus Conference. London: International Planned Parenthood Federation, Arab World Region, 1993.

45. World Health Organisation (WHO). Research of major maternal mortality causes of Turkey from the hospital records Ministry of Health. Ankara, Turkey: Public Health Department of Hacettepe University, 2000.

46. Chaudhuri SK, and International Contributors. Practice of fertility control: a comprehensive textbook. 4th edn. New Delhi: B.I Churchill Livingstone, 1996.

47. Laufe LE, Husman C, Kessel E, Briton LA. Menstrual regulation: A new family planning service. Western Pennsylvannnia Hospital Medical Bulletin 1974; 8(1): $3-8$.

48. Laufe LE. Menstrual Regulation — International Perspective. In: Zatuchni GI, Sciarra JJ, Speidel JJ (eds). Pregnancy termination, PARFR series on fertility regulation. Hagerstown, MD: Harper \& Row, 1979: $78-81$.
49. Begum SF, Kamal H, Kamal GM. Evaluation of $M R$ services in Bangladesh. Dhaka, India: Bangladesh Association for Prevention of Septic Abortion (BAPSA), 1987.

50. Bhatia Sushum, Faruque ASG, Chakraborty J. Assessing menstrual regulation performed by paramedics in rural Bangladesh. Stud Fam Plann 1980; 11(6): 213-218.

51. Grimes DA, Benson J, Singh S, et al. Unsafe abortion: the preventable pandemic. Lancet 2006; 368(550): 1908-1919.

DOI: 10.3399/bjgp08X280353 